


\section{Las palabras \\ que nos hacen. \\ Relato de vida de una maestra de infantil}

Mari Carmen Díez Navarro ${ }^{1}$

La palabra es la chispa sonora de la vida, es lo que baila, alegre, en el fluir inmenso.

La palabra es calor,

es juguete, es tejido.

Es el bendito nido de mi inquieto deseo, quien no me deja sola, quien me quiere.

Me han pedido que me lea y que me escriba. Que explique, que presente, que hable de un recorrido escritor que ya tiene su sabor, que ya camina solo.

Esto de "Las palabras que nos hacen" es una idea muy sugerente, que recoge algo sentido por mí, aunque no lo bastante explicitado hasta el momento. $Y$ es que creo que a medida que he ido escribiendo, he visto que las palabras me devolvían más de lo que yo creía haberles dado. Al leerme, noto que ellas han capturado e incluido la parte más intuitiva y creativa de mi pensamiento, lo que me caracteriza, lo más mío.

Porque vivir mi práctica educativa en la escuela, pensarla y plasmarla por escrito, han sido tareas que yo sabía que estaba haciendo. Pero al leerme a mi misma, me he encontrado con algunos sentires que apenas conocia, con inesperadas conexiones y con sorprendentes chispas que me han hablado de mí, de mis preferencias, mis emociones, mis errores, o mis agujeros.

Voy a tratar, pues, de hacer de aposentadora de mis páginas, de mis palabras y de mis gotas de poesía. Señalaré algunos caminos para escudriñar los entresijos de mis relatos, una llavecita que abra curiosidades, un foco de luz que permita encontrar los lugares en los que se asientan mis maneras de sentir la escuela.

1 Maestra de Primera Enseñanza, especialista en Educación Infantil y licenciada en Psicopedagogia, Universidad de Alicante. tomasetti@telefonica.net 


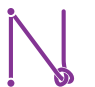

Volumen 6 N. ${ }^{\circ} 48$ enero - junio de 2020 ISSN: 0122-4328 ISSN-E: 2619-6069 pp. $150-172$
Contaré qué es para mi escribir, por qué cuento lo que cuento, qué tiene que ver mi oficio de maestra con mis escrituras, y qué palabras son las que "me han hecho". También contaré algo sobre "los hechos que se me han vuelto palabras", los que conforman el relato de mi experiencia de vida. Lo haré con algunos de mis escritos, con un poco de mi historia y con bastantes de mis sentimientos...

\section{Los hechos que se vuelven palabras}

\author{
El oficio del maestro es escuchar \\ acompañar asombros \\ vestir los saberes de mañanitas. \\ El oficio del maestro es aprender (y aprenderse) \\ es contar (y contarse) \\ es soñar (y soñarse) en el \\ festín de estrenar con los niños \\ la alegria del conocer
}

Ser maestra me viene de madre. Ella era una maestra de un estilo, de un color, de una forma... Yo he gastado otras maneras, pero sin duda alguna su influencia y su buen manejo en el oficio, me han facilitado crear mi propio modo de hacer escuela.

Mi madre nos tenía la ropa clasificada en dos categorias jamás intercambiables. Por un lado, estaba la ropa de vestir y por el otro la de todos los días. Así que ni pensar en que un miércoles pudiéramos ponernos alguna de las prendas de los domingos o que un domingo nos vistiéramos "de cualquier manera".

Días y ropas estaban, pues, previstos, prefijados y predestinados a ser vividos según su categoría correspondiente. Todo era orden, todo era ley, todo era "lo que debía ser". Sin embargo, a mi esta costumbre de clasificar la ropa me resultaba un poco dificil de entender y más bien se me antojaba un mandamiento extraño e incomprensible. Sentía las leyes de las ropas de un modo bastante ambivalente. Por una parte, me ofrecian seguridad, contención y "no sobresalto"; por otra, atadura y negación de mis deseos. En este asunto no habia ni un resquicio para las negociaciones, estas leyes eran inamovibles.

El caso es que, seguramente por lo vivido, desde que me reconozco, siempre he tenido más despiertas de la cuenta las ganas de cambiar las cosas, de asombrarme, de vivir novedades... e incluso de transgredir. 
Por eso también he buscado, y busco, maneras de ser y de estar en la escuela que dejen paso a opinar, a elegir, a inventar... Que hagan sitio a unas normas entendidas y aceptadas. Y que permitan, a ratos, alguna alteración del orden prefijado en aras de darse algún que otro respiro, a volar y tocar tierra...

Busco una forma de estar en la escuela en la que se pueda vivir el día a día con la sensación de que en cualquier momento puede saltar una chispa, puede brillar un asombro, puedes ponerte el vestido de vestir o los tacones nuevos... Porque ir "de diario" es confortable, sí, pero siempre que la comodidad no alcance a ahogarte los deseos.

Buscando, buscando... he encontrado una escuela en la que los dias de cada día son siempre diferentes.

Pueden traer sorpresas, descubrimientos, lágrimas.

Pueden traer ideas, explosiones, sonrisas.

Pueden traer un libro, un conejo, una pregunta buena.

Pueden traer miradas, encuentros, trabajo, juego y emociones.

Yo les noto ese brillo que me anima y me sirve, esas gotas de nuevo que me traen esperanza. Y me alienta el chispeo de mañanas y tardes que percibo, felizmente, como una cotidianidad recién nacida. (Díez Navarro, 2007, p. 295)

Durante 46 años he estado recorriendo este buen oficio. He trabajado dando clases de cultura general, de alfabetización de adultos, de educación especial, he hecho sustituciones, he dado clases particulares y he pasado por prácticamente todas las edades y etapas educativas, hasta que llegué a estar con los habitantes más pequeños de la escuela. Y aquí me quedé. Me maravilla verlos transitar desde el mundo primitivo y mágico, al más social y civilizado. Desde el no hablar hasta el razonar, desde el más puro narcisismo hasta el mirar con afecto a los demás. Me gusta el momento y en él me he afincado para disfrutar del espectáculo.

Para llegar aqui ha habido mucho aprender, mucho compartir y mucho practicar. Una historia de vida con momentos significativos para el tema que nos ocupa, porque naci en una escuela; tuve una familia narradora; lei gratis muchos años en el kiosco de unos amigos; me dio clase de lengua y literatura Don Francisco, un magnífico profesor; pasé horas con unas amigas, Aurora y Ceci, con las que inventaba cuentos y "películas"; aprendi de mi tía Horten muchas pistas para hacer historias, etc., etc.

En el recorrido ha habido muchas reflexiones, dudas, intuiciones y errores. También ciertos hitos que, a pesar de mis resistencias y mis miedos a lo nuevo, me han supuesto desde pequeños vuelcos a verdaderas revoluciones. Personas, ideas y hechos que me han llevado a comprender, a elegir caminos y a cambiar. 


\section{El oficio del maestro es aprender}

En la escuela, como en la vida, hay días nublados, en los que se tuerce el corazón a golpe de desastres, de inseguridades, o de errores solemnes... Y dias claritos, en los que se te espabila el alma sin poder evitarlo. Voy a intentar aquí contar algunas historias chicas que me han pasado en las aulas recorridas a lo largo de estos años, para disfrutar otra vez con su recuerdo y para invitar a mis compañeros, los maestros de a pie, a reconocer como bueno este oficio nuestro tan vivo y tan cambiante, en el que uno puede gustar de escudriñar saberes, de acompañar cariños y reestrenar palabras... con los alumnos.

Volumen 6 N.o 48 enero - junio de 2020 ISSN: 0122-4328 ISSN-E: 2619-6069 pp. $150-172$
Mirando hacia atrás, lo primero que tendría que decir es que yo empecé a prepararme para ser maestra muy tempranito (y el tiempo, en estas cuestiones de los oficios, es muy importante...). Según me cuentan, recorría el pasillo de la escuela de mi madre, probando a dar lecciones a los muñecos, hasta que, metida en el engranaje de esa especie de escuela escalonada que organizaba ella (para tenernos ocupados a todos, creo), fui aprendiendo a manejarme con los demás niños en el juego continuo que suponía ser maestro y alumno simultáneamente.

Alli aprendi a buscar mis propios recursos para explicar las cosas, a leer en voz alta y clara para que me entendieran y, atendieran, los más pequeños cuando les leía un cuento, a hacer "buena letra", a gesticular teatralmente, a soportar ser la última para casi todo (tenía que dar ejemplo) y a aprovechar cualquier ocasión para soñar. Bueno..., también aprendi a reñir. Como se puede ver, todas ellas herramientas muy útiles para el trabajo que nos ocupa.

La primera vez que hice de maestra de verdad fue cuando tenía diecinueve años. Entré a trabajar en una unitaria con cuarenta y ocho niños y niñas entre los seis y los catorce años. Eran tantas las ganas que tenía de hacer las cosas a mi manera, que llené las pizarras de planes y de inventos, para que todos pudieran aprender mucho, enseñar un poco y pasarlo bien en compañia de los demás. Y ahi fue cuando me di mi primer tropezón con la realidad, que, sin embargo, me enseñó algo importante ya que, huyendo de las exigencias absurdas de la dirección de la escuela, aprendi a resistir, y a enterrar mis deseos a pesar de las dificultades. En estas historias de aula no se puede dejar de incluir lo sucedido uno de aquellos días, que, por cierto, acabó de manera bastante sorprendente.

Eran las cuatro y media, la directora acababa de irse con los portazos, trompicones y advertencias agrias de siempre: que si han leido los pequenos, que si han hecho dictado los mayores, que cuantas veces he dicho que no se sienten en grupitos, que cómo es que hay juguetes en la clase, que qué es eso de que los mayores les cuenten cuentos a los pequeños. Normalmente, cuando esto pasaba, se hacía un grueso silencio, yo me ponía muy colorada y se me apretaba un nudo en la garganta, que no me dejaba ni argumentar. Sin embargo, aquel día no era como los otros. Teníamos un plan. Un inaudito plan que nos comprometía en un secreto alegre a las tres alumnas mayores de la clase y a mí. 
Lucia, Marta y Toñi quieren saber "de donde vienen los niños y todo eso", y como en el colegio existía una prohibición expresa de hablar de sexualidad, les propuse venir a merendar a casa, y explicárselo con calma. Los padres estuvieron de acuerdo, por eso estábamos tan contentas. Lo que ninguna de nosotras esperaba era que el plan acabara de esa manera. Después de la merienda y de la explicación, me puse de parto prematuramente, con lo cual las niñas tuvieron un acercamiento al tema de lo más real y significativo. iQué cosas! La que se llevó un buen berrenchín fue la directora: "iQué bochorno! ¡Qué vergüenza!", iba diciendo. Los demás, en cambio, nos alegramos mucho.

Han seguido otras escuelas y en cada una de ellas he podido aprender, entusiasmarme, divertirme, equivocarme, dudar... En casi todas he podido encontrar algún compañero con quien compartir la tarea, algún padre o madre con quienes pensar sobre la educación, algún niño o niña con quien asombrarme, a quienes admirar, a quien rodear de esperanza. Y esas cosas te acompañan por dentro, te hacen más fácil la profesión, te llenan de deseos de seguir adelante.

Recuerdo vivamente a Isidro, un niño de nueve años, paralitico cerebral cuando se cayó de la silla, al dar un brusco aspaviento, porque había oído que alguien decia que no nos lo llevariamos de excursión, ya que "se atragantaba demasiado al comer y eso era un problema". No puedo olvidar cómo me miró, y cómo se hizo entender sin palabras, imprimiendo a su mirada toda la rabia, la impotencia, la demanda, la pena.

También recuerdo a Juani, una alumna de sesenta años que lloró de alegría al conseguir leer el nombre de su calle, expresando con esa frase simbólica su entrada en la cultura: "iYa no soy ciega!". Y a Rafa, que se asombró al aprobar por primera vez un examen de lengua: "Pero si yo pensaba que era tonto!"

Recuerdo las reuniones de padres que organizaba mensualmente Alberto Barrios, amigo y maestro, que se convirtieron en un auténtico foro de reflexión conjunta con las familias. En una de ellas escuché decir a un padre este comentario dificil de olvidar: "; Qué envidia me da mi hijo! Él puede estar aqui todos los dias y hablar y aprender con los otros. Yo no tuve esa suerte; esta es la primera escuela que piso en mi vida.

Veo

Veo a los más pequeños jugar, preguntar, mirar, aprender. Los veo imitarse, hasta que se atreven a ser como son, hasta que deciden a mostrar que son distintos, hasta que se convencen de que son valiosos en su particularidad única. Los veo descubrir la vida poquito a poco, investigando cada gesto, cada interrogante, cada deseo. Los veo entrenarse en reconocer lo que sienten e ir aceptando lo que sienten los demás. Los veo, en fin, empezar a recorrer su propio camino. Y me gusta el espectáculo.

Me veo a mi misma preparando materiales, discutiendo, observando al alimón con mis compañeros del momento... Me veo haciendo informes, calibrando cómo encarar una entrevista para lograr entenderme con los padres, preocupándome de por qué Alba aún juega sola, por qué Roberto apenas habla, por qué Juan se pasa el día pegando y molestando a los 


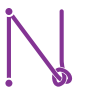

Volumen 6 N. ${ }^{\circ} 48$ enero - junio de 2020 ISSN: 0122-4328 ISSN-E: 2619-6069 pp. $150-172$ demás... Me veo pringada de pintura, de pastel y de risas. Me veo leyéndoles poesías, bailando con ellos, haciendo teatro... Alentando sus valiosas discusiones, como aquella de si era bueno o malo ser presumidos, o la de si se tiene que jugar con quien tú no quieres o te puedes separar...

Me veo también, en los tiempos nublos, con mis resistentes dificultades para aceptar no ser tan querida, tan imprescindible, tan escuchadora como quisiera... Me veo cabezota, llena de prisas, poniendo excusas para no tener que asumir mi propia ignorancia... Me veo rehuyendo el papel (necesario) de controladora, de señaladora de limites, de frustradora de deseos, de detectora de problemas...

Me veo calmando a Adriana que no quería morirse porque "eso está muy oscuro", moderando la indignada asamblea que se quejaba de los desmanes de Pablo, escuchándole la rabia a Marta, celosa ante el nacimiento de su segundo hermano, riéndome al leer la carta que se escribió Manuel a sí mismo, y que decía escuetamente "Aupa Manuel". Emocionándome al oír cómo se despedían Javi e lgnacio una de las últimas tardes de este curso pasado:

Ignacio: Voy a ir a un colegio con piscina imanizada.

Javi: Será imatizada.

Ignacio: Bueno, sí.

Javi: ¡Ay!, pues yo me iría contigo a ese colegio.

Ignacio: Lo dices por la piscina, ¿verdad?

Javi: No, lo digo por ti.

Porque como decía Álvaro Cunqueiro, "cosas asi solo pasan en los grandes amores".

Me veo, en fin, afectada de tantos afectos que discurren a mi alcance que no puedo por menos que reafirmarme en mi deseo de seguir en esa profesión llena de encuentros, de asombros y de curiosidades jugadas en comandita.

\section{A lo largo del tiempo}

Desde que empecé en este oficio ha ido cambiando mi modo de entender la educación. He ido bajando muchos escalones, tarimas, pedestales. He ido pasando por muchos miedos, dudas, inseguridades, errores. Cómo no, por infinitas pruebas, métodos, cursillos y debates. Y por el trabajo en solitario. $Y$ en grupo. Y por lecturas y lecturas. Y por personas y personas.

Todo ello me ha llevado a acumular muchos recursos didácticos, mucha costumbre de estar en clase, muchos ejemplos y otras cosas más. Pero yo creo que ha sido el poner la oreja atenta y escuchar lo que dicen los niños lo que me ha dado la clave para saber cómo irme manejando en este momento. Asi que, guiada por sus pequeñas voces, ahora entiendo la escuela como un sitio donde vamos a aprender; donde compartimos el tiempo, el espacio y el afecto con los demás; donde siempre habrá alguien para sorprenderte, para emocionarte, para decirle al oído algún secreto magnífico. 
Y lo demás... solo es pedagogía. Ir probando y probando maneras de estar en la clase. Tantear qué va mejor o peor a la hora de plantear las tareas concretas. Cuestiones de forma, de método, de planificación, de librico.

Sin embargo, a mi modo de ver, lo importante es otra cosa. Si podemos mostrarnos como somos y contagiar a los niños algunas de nuestras apasionadas relaciones con los libros, las montañas, el saxofón, o el punto de cruz..., qué más dará si elegimos las letras grandes, o las chicas, los talleres integrales, o los rotativos, los papeles redondos, o de lunares...

Sin ir más lejos, a mi me gusta cantar, bailar, y recoger tesoros. Me gusta leer, escribir y preguntarme el porqué de las cosas. Me gusta la poesía, las cajas, estar con los amigos, el mar... Y reirme, y aprender, y jugar con los niños...

$Y$ aunque no puedo demostrar que esto tenga que ver con el buen hacer de la profesión, estoy tan segura de ello que siempre que puedo propongo una escuela donde la gente hable, se relacione, comparta lo suyo, lo pase lo mejor posible y aprenda, en compañia de los demás.

\section{"Hacer de maestro"}

Creo que "Hacer de maestro" es una tarea rica, entretenida, arriesgada y apasionante. Aunque hay muchas maneras de llevar adelante nuestro oficio. Según los presupuestos teóricos en que te apoyas, según como fueron tus inicios, según el tipo de escuela que sueñas, según la escuela concreta en la que estás trabajando, según las modas pedagógicas, según tu momento, tu edad, tu sexo, tu situación familiar, tus limitaciones, tus virtudes, tu grado de deseo en seguir implicado activamente en la profesión...

En este momento podria decir que concibo mi tarea de maestra como un acompañamiento, una escucha y un contagio. Como un asunto de vida, de vínculos, de ser y no solo de estar.

Hace unos meses participé en un curso en el que debía decir algo sobre el quehacer del maestro. Para ello se me ocurrió hacer un listado de "tipologias" de maestros en tono humoristico, inspirándome en chistes de Frato y en otros dibujos aparecidos en revistas pedagógicas. Los dibujantes habian caricaturizado con tanta gracia nuestras manias, nuestros estilos, nuestras preferencias e ignorancias, que cualquiera de nosotros podiamos vernos reflejados en uno o más de los grupos representados. Mi demanda en aquel seminario era preguntarse, con una sonrisa, a qué tipo de maestros nos parecíamos más:

¿Maestros titiriteros? ¿Maestras ilusionistas? ¿Maestros innovadores? ¿Maestras abiertas al cambio? ¿Maestros tradicionales? ¿Maestras evaluadoras? ¿Maestros uniformadores? ¿Maestras miedosas? ¿Maestros asépticos? ¿Maestras perfeccionistas? ¿Maestros programadores? ¿Maestras "espontaneistas"? ¿Maestros duros? ¿Maestras malhumoradas? ¿Maestros alegres? ¿Maestros apóstoles? ¿Maestras deprimidas? ¿Maestros "quemados"? 
¿Maestros científicos? ¿Maestras ecologistas? ¿Maestros técnicos? ¿Maestras controladoras? ¿Maestros permisivos? ¿Maestras psicomotoras? ¿Maestros "en equipo"? ¿Maestras constructivistas? ¿Maestros "freinéticos"? ¿Maestros legalistas? ¿Maestras reflexivas? ¿Maestros acompañantes? ¿Maestras intuitivas? ¿Maestros responsables? ¿Maestras "funcionarias"? ¿Maestros "de las fichas"? ¿Maestras investigadoras? ¿Maestros esperanzados?

¿Maestras de los valores? ¿Maestros de la educación vial? ¿Maestras del reciclaje? ¿Maestros "animadores a la lectura"? ¿Maestras de la paz? ¿Maestros de la diversidad? ¿Maestras de la coeducación? ¿Maestros de la educación ambiental? Mientras preparaba el listado reflexionaba sobre mi misma en la escuela. Me preguntaba qué clase de maestra era yo, en qué grupos me sentía incluida. Y me pude dar cuenta de cuáles de aquellas imágenes o nomenclaturas me hacian cuestionarme, cuáles me inquietaban o me fastidiaban, cuáles me daban risa, o pena...

Porque a mi modo de ver se puede ser maestro de muchisimas maneras, pero lo que no se puede, ni se debe es ser maestro "sin ser". Sin "ponerse a ello", sin implicarse, sin vivir la relación educativa como lo que es: una relación entre personas. Una relación en la que hay dos elementos de los que no se puede prescindir: los maestros y los niños.

Estar en la escuela pendientes solo de "los saberes" equivale a hacer una escuela con una ausencia fundamental: nosotros mismos. Hacemos falta, sí, pero no como dispensadores de instrucción y destrezas, sino como personas "enteras y verdaderas" porque los niños necesitan no solo ser "enseñados", sino también ser mirados, escuchados, atendidos, acompañados, queridos... Necesitan que se les auguren y deseen buenas cosas. Que se les respete su identidad creciente y diferenciada. Que no se les inunde con excesivas demandas, ni depositaciones de los deseos de otros (padres o maestros). Que se les incluya en el grupo social. Que se les otorgue un lugar.

Un maestro bueno ha de ser:

Según los niños:

» Para ser un maestro bueno hay que trabajar mucho.

» Una maestra buena es la que deja jugar y la que enseña a leer; y si tienes un hermano, es la que te lo tiene que cuidar bien.

» $Y$ tiene que portarse bien y cuidar mucho.

»Y enseñar a pintar.

»Y preparar cosas para que los niños las hagan.

» Las maestras tienen que trabajar, pintar y enseñar a los niños muchas cosas, juegos y canciones.

» $Y$ tienen que aprender a usar las pizarras y los ordenadores.

» $Y$ cuando vayan al patio, que nos vigilen.

» $Y$ cuando nos salga algo mal, que nos ayuden. 
»Y que se porten bien "ellas", y que tengan cuidado de los pequeños que arañan a los mayores.

» Para ser un maestro bueno hay que cuidar a los niños.

» Para ser una maestra buena hay que tranquilizarse.

» $Y$ arreglar las clases bonitas, y juntar mayores con pequeños, y cuidar que los pequeños no muerdan a los mayores.

»Ni les escupan.

»Las maestras buenas tienen que resolver las peleas, o castigar si el niño repite lo malo tres o cuatro veces.

»O hablar.

» $Y$ tienen que tener "deportividad"

$»$ ¿Y eso qué es?

»Pues no pegar, ni hacer la zancadilla, ni hacer trampas, ni en el fútbol ni en clase...

$»$ ¿Pero ella...?

» Sí, ella, y también que no deje que hagan todo eso los niños de su clase.

» Y que no dejen, ni permitan que los niños saquen las raíces.

»Ni trepen las vallas.

» Las maestras lo que tienen que hacer es educar a los niños. Eso quiere decir explicarles las cosas, todas las cosas.

\section{Según Albert Camus (1994):}

En la clase del señor Bernard por lo menos la escuela alimentaba en ellos un hambre más esencial para el niño que para el hombre, que es el hambre de descubrir. En las otras clases les enseñaban sin duda muchas cosas, pero un poco como se ceba a un ganso. Les presentaban un alimento ya preparado rogándoles que tuvieran a bien tragarlo. En la clase del señor Bernard sentian por primera vez que existian y que eran objeto de la más alta consideración: se los juzgaba dignos de descubrir el mundo. (p. 128)

\section{Según J. L. Sampedro (1992):}

Para ser un buen maestro hace falta imprimir al hecho educativo de "amor y provocación, aparte, claro, de los conocimientos imprescindibles"

\section{Según Rabindranath Tagore (1966):}

Con Satir, el maestro, los muchachos no se sintieron nunca sujetos a un determinado aprendizaje, sino que parecian tener entrada en todo. En primavera, cuando los árboles de sal estaban llenos de flor, Satir se iba al bosque y alli les recitaba, frenético de emoción, sus poemas favoritos. 
Nunca sintió la menor desconfianza de la capacidad de los muchachos y les hablaba y leía de cualquier asunto en el que estuviesen interesados.

Su anhelo era despertarles el entendimiento y siempre tenía éxito. Su enseñanza era personal y él mismo la fuente de ella, y asi estaba hecha de la materia de la vida. (p. 1232)

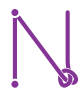

Volumen 6 N. ${ }^{\circ} 48$ enero - junio de 2020 ISSN: 0122-4328 ISSN-E: 2619-6069 pp. $150-172$
Los maestros hablamos de nosotros mismos cuando organizamos, cuando reñimos, cuando observamos, cuando corregimos, cuando hablamos, cuando enseñamos, cuando aprendemos, cuando estamos con los padres de nuestros alumnos, cuando estamos con otros maestros... Hablamos de nosotros mismos con la ropa que nos ponemos para ir a la escuela, con nuestra voz, nuestros gestos, con los materiales que escogemos para el aula, con la forma de decorarla, con las fotos que hacemos, con nuestra manera de poner las normas y de estar en la escuela...

Si observáramos a un maestro o maestra, podríamos hacernos una idea de cómo es, qué le preocupa o le interesa más, cuál es su modelo educativo, cuál es su estilo. Desde lo más sencillo, como puede ser el atuendo, hasta lo más complejo, como serian las teorías que subyacen a su práctica. Desde lo más externo, como puede ser la decoración y estética de su clase, hasta lo más interno, como serian sus criterios de observación o intervención. Desde lo más cotidiano, como pueden ser los materiales que elige, hasta lo más institucional, como sería su planificación del currículum, sus elecciones metodológicas, su papel en el equipo de docentes.

Si yo quisiera decir de mi manera de ser maestra, tendría que contar algunos de mis recursos, de mis trucos y de mi modo de entender la relación educativa.

\section{Soñar despierta}

Me piden que desgrane en unas cuantas palabras lo que da su particular acento a mi manera de estar en la escuela, al estilo con el que trabajo, a mi manejo de las situaciones, de los vínculos, a mi enseñar y a mi aprender. $Y$ me veo mirándome a mi misma con unos ojos de lo más indiscreto, tratando de leer en mis actuaciones y pensamientos cotidianos todo aquello que los ha ido conformando y sustentando, pero que, a fuerza de estar tan bien instalado en mi "adentro", no sé si a tinaré a recitar en voz alta.

He titulado el escrito con una frase que este curso hemos manejado bastante. La descubrió Jaume, viendo una película, y nos la explicó asi:

Ayer aprendi a hacer una cosa nueva: soñar despierto.

¿Y eso cómo se hace?

Pues se cierran los ojos y te imaginas todo lo que tú quieras iy hasta se puede hacer con los ojos abiertos, que ya he probado!

Qué buena idea, Jaume, gracias por contarla. ¿Lo intentamos? 
Las brillantes imágenes, y las bonitas historias florecieron en abundancia, y no solo ese día, sino el resto del año. Incluso fabricamos "La caja para soñar despierto", cuyo uso era imaginar libremente a partir de los objetos que aparecian en su interior. En la caja cada cual metía (un poco secretamente): pequeños juguetes, flores, canicas, monedas, muñecos, palos, caracolas, botones, piedras... para enriquecer los productos imaginativos resultantes de ese soñar despierto que tanto nos habia gustado. Asi lo conté en su día en el Diario de clase: Veo que cogen la caja entre varios, todos ellos muy amantes de las imaginaciones y van hilando historias, aún sin la suficiente coherencia, pero con frases largas y poéticas, que tienen memorizadas de relatos o películas: "Era el tiempo de las lluvias y los volcanes...", decía sentidamente Joan. Qué buen comienzo.

Soñar y "estar despierto" a la vez, me recuerda a la actitud realista y a un tiempo "soñadora" que considero que "hay que tener" en este buen oficio de maestros, que viene a ser como una artesanía. Como un tejer tapices con hilos cotidianos y con hilos de lujo, con hilos sentimentales y con hilos del conocimiento, con hilos del ofrecer y con hilos del recibir, con hilos de pisar tierra y con hilos de volar, persiguiendo el deseo de hacer una escuela ... amable.

Mantengo con mis alumnos un vinculo hecho de palabras, inventos, bromas, ley y cariño. Un vinculo cordial y divertido, en el que tienen lugar preferente las sorpresas, los juegos, el trabajo, las relaciones, las historias y el soñar "en comandita". Los espero hasta que van entendiéndome las formas de hablar extravagantes que gasto, los dobles sentidos de mis bromas, las pequeñas metáforas de mis poemas pareados, mis sugerencias de trabajo o de juego. Y cuando ya están "en ello", me acompañan los vuelos, me sorprenden con sus "pinitos" y me ayudan a crear un clima de buen estary placer.

Si lo intento desmenuzar "pensándome" en la clase, lo primero que me viene como una fuerte presencia es la risa, la mía y la de los niños. El meterme con la exhaustiva "pelada" de Sergio, con los lazos "de papagayo" de Marta, o con la cara de "manzanitas agrias" que trae Anselmo por las mañanas. Empezamos el día con risas y asi lo vamos pasando. El buen humor es tan indispensable para el ambiente sano de cualquier grupo... El caso es que nos reimos bastante y con las risas, se va entretejiendo el trabajo, importante eje aglutinador en nuestra marcha diaria.

Lo que "me llega "a continuación es el aire musical y poético en que tengo envuelto todo lo que me rodea, sin poderlo, ni quererlo remediar. La música es una de mis aficiones preferidas y normalmente la llevo conmigo "puesta" tarareando, zapateando, o lo que se tercie. Así que, en mi aula siempre tenemos la música a punto. Con audiciones clásicas, con cha-cha-chas, o con mambos. Con melodías que los niños traen de sus casas, o con las que llevo yo. Pero música, música y música, que nos anima, que nos consuela, que nos hace bailar, cantar, o darle a las palmas todos a una.

Y con la poesía... cómo podría decirlo. Mi relación con la poesía es muy estrecha, me apasiona leer y escribir poesía, y el afecto que pongo en ello, 
moviliza el interés en los niños y les hace acercarse al mundo poético de una particular manera. Las aficiones personales metidas en el aula son muy buenas de aprovechar. El caso es que por un lado la belleza y el poder de los poemas y por otra el afecto con que son transmitidos, logran año tras año "el milagro" de que se vivan en "onda poética" los aconteceres cotidianos. Y lo que empieza con bromas "en verso": "Chiquillas, hay bocadillos de bombilla", o pareados con los nombres de los niños: "Mireia se ha hecho amiga de una estrella de color verde botella", acaba con lecturas de García Lorca, o con preciosos poemas creados por los propios niños.

Volumen 6 N. ${ }^{\circ} 48$ enero - junio de 2020 ISSN: 0122-4328 ISSN-E: 2619-6069 pp. $150-172$
Sin embargo, creo que es el tratamiento de los temas afectivos, los del "piso de abajo", como yo los Ilamo, lo que podría ser la tónica de mi tarea, de unos años aquí. Pretendo, por encima de otras cosas, lograr un vínculo claro y cercano con cada uno de los niños, y en el proceso voy notando que entre ellos y yo se va formando una especie de hilo "de palomar", oscurito, seguro y resistente, que nos une y nos confirma en cada momento que vamos juntos en esta aventura de aprender y descubrir.

Cada cual sabe y capta que lo tengo en cuenta, que me importa, que lo reconozco distinto a los demás y que me gusta que lo sea. Como grupo saben que hay una "manera de estar", que yo propongo y vamos matizando entre todos, y que alude a hablar de las cosas que pasan, a verbalizar lo que se piensa y lo que se siente, a aceptar los acuerdos y las normas, a cuidarnos, escucharnos, respetarnos, a trabajar y a divertirnos. Saben también que yo no soy una más en el grupo, sino que tengo un papel diferente y que puedo cobijarlos y controlarlos, enseñarles y reñirles, enfadarme y bailar con ellos.

De esta manera ofrezco la posibilidad (creo...) de que todos piensen, opinen, y vayan empezando a manejarse como personas que ensayan independencia. En este ambiente de escucha surgen desde propuestas de trabajo, a resoluciones de peleas. Desde declaraciones de cariño, a preguntas por la muerte. Desde furibundas críticas, a narración de experiencias, o sueños. El grupo vibra, se muestra vivo.

$Y$ aunque con frecuencia no sé si mis intervenciones han sido o no las indicadas, he perdido bastante el miedo, y me siento cómoda, tranquila y a gusto en la clase, sabiendo que me equivocaré, que dejaré de aprovechar cosas aprovechables, que tendré que "limitar" a algunos, "empujar" a otros, mirarlos a todos, pero que, como no soy omnipotente, no siempre me irá todo a las mil maravillas. Y no pasará nada terrible, porque los maestros, aunque no esté escrito en los cánones, también tenemos derecho a equivocarnos.

Cuando pienso en preparar una clase o en planificar un día, tengo en cuenta varias cosas: la línea pedagógica de la escuela, el proyecto educativo, los contenidos del currículum, los tiempos, los espacios, los materiales, las metodologías..., pero en lo que me fijo principalmente es en mis alumnos. En su tendencia a hablar, a callar, a moverse, o distraerse. En sus preferencias, en su edad, en sus pequeñas historias, y hasta en sus nombres, en sus 
caras, en sus ojos... También me fijo en la dinámica de funcionamiento del grupo: su grado de cohesión, su autonomía, sus movimientos de cambio o de resistencia, su manera de "estar", los subgrupos que lo conforman, los lideres naturales...

$Y$, desde luego, me tengo en cuenta a mi misma, porque he comprobado que estoy más tranquila y emprendo la tarea con mejor disposición si me "respeto el gusto" y no me pongo más obligaciones de las indispensables. Hay veces que tengo pensado un plan, elaborado a partir de las propuestas de los niños o de las mías, pero de pronto se me ocurre que podríamos hacer otra cosa, Pues bien, hoy en día, hago caso a mis deseos y a mis "inspiraciones súbitas." Antes no solía permitirme estas "transgresiones", estos pequeños placeres de adelantar o retrasar un trabajo, esta posibilidad flexible y siempre abierta de cambiar el horario, la actividad, de saltarme lo previsto y hacer algo nuevo. Me sonaba a falta de responsabilidad, a culpa, a excesivo espontaneismo, a desorganización, a que les quedarian "lagunas" insalvables a los niños a causa de mis corazonadas. En cambio, resulta que es casi al revés, veo que cuando recibo o transmito algo que me ilusiona, sale mejor. Asi es que ahora me fío del valor de mis contagios, que no sé si serán muy pedagógicos, pero sí son bastante humanos.

De hecho, en el trabajo por proyectos, que es el que hago hace ya tiempo, los niños y yo planeamos juntos lo que queremos hacer, averiguar o aprender. $Y$ en este ambiente de tarea conjunta, de conversación continuada y de relaciones abiertas, veo que realmente da lo mismo que hagamos un día u otro los teatros que propuso Iván sobre animales salvajes, o la jirafa gigante que quería construir Leo. Porque he comprobado una y otra vez que hagan lo que hagan, aprenden, mejoran, crecen y disfrutan. Es por eso que me permito el lujo de incluir lo que ocurre y dar paso a las ideas, los sueños o los cambios que surgen, ya sea a partir de los niños, de mi misma, de las familias, o "del exterior" ¿El objetivo no es aprender juntos placenteramente?

En mi práctica diaria manejo muchos recursos, que son tan variados y estrafalarios como yo misma. Uno de los más "propios" es la imaginación. Desde que me reconozco me gusta inventar y lo hago sin ninguna inhibición en clase con los niños, que primero se asombran, después se rien, y muy pronto empiezan a aventurarse también en esto del soñar despiertos, del idear y usar la fantasía para animar las realidades. Asi pues, imaginamos juntos creando historias, haciendo improvisaciones teatrales, dibujando...

Otro recurso que utilizo son mis recuerdos y mis experiencias, a los que acudo confiadamente como el que va a una tienda de materiales de alto diseño. Alli siempre encuentro algo que me conecta con los niños que tengo delante, haciendo, medio sin darme cuenta, una sintesis en la que alguna experiencia vivida por mí, se reúne con algún interés suscitado entre los niños. Cuando están en plena caída de los dientes, por ejemplo, les cuento alguna historia que me pasó a mi, a mis hijos, a mi hermano... Cuando alguien habla de sus miedos, les confieso lo que me asustaba a mi de 
pequeña, o lo que me asusta ahora. Cuando curiosean mirando, preguntando o...escuchando lo que hablamos las maestras, les reconozco lo curiosa que siempre he sido y que soy, y les cuento que incluso llegaba a esconderme debajo de la mesa camilla de mi abuela para enterarme de lo que se decía. Y esas historietas, cargadas de afecto y de significado, nos van cohesionando y animándoles a ellos a contar también sus vivencias, logrando asi crear un ambiente de grupo entre todos.

Contar cuentos es uno de mis recursos favoritos. Me agrada regalarles a los niños el gusto por las palabras, para que asi puedan poco a poco acceder a los contenidos simbólicos que transmiten las historias, que les ofrecerán un amplio abanico de comportamientos y tipos humanos, de situaciones, de posibles identificaciones. Y para que disfruten con ellas, claro. Suelo contar el mismo cuento durante los cinco días de la semana, a la misma hora, y en medio de un silencio que al principio cuesta de conseguir. Los cuentos que les cuento están elegidos cuidadosamente, "comprobados" en su calidad y sus "efectos" por años de contarlos. Incluso están tapados y envueltos en una mantita (tejida por la abuela de David)... "para que no se enfrien". Los hay de muchos tipos, pero siempre han de decir algo, siempre han de "atrapar", siempre han de abrir las ganas de seguir escuchando. De vez en cuando el cuento es contado de viva voz y sin apoyo visual alguno. Son los cuentos de mi infancia, los que me contaba mi madre. Ésos son los de más fiesta. Siempre que hay un rato libre me los piden: Blancabella, Los tres pelos del diablo, La mano negra, El hombre del saco... Para mi es un placer notar el círculo tan cerrado y los oídos tan abiertos.

Considero que el juego es otro recurso imprescindible. Los niños lo necesitan, si juegan están mejor, tienen más iniciativas, están más tranquilos, se relacionan más saludablemente... Dando un tiempo y un espacio para jugar les hago saber que los respeto. Así que dos veces a la semana hay "juego libre" en mi clase. Estos ratos son suyos, yo me dedico a mirar y a anotar a lo que juegan, con quien o cómo. A veces juegan con las muñecas, los coches, la cocina, las construcciones, la tienda, o se disfrazan, se esconden, se peinan, luchan, bailan, van en patinete, en zancos o en bicicleta. Otras veces los juegos son de movimiento, de reglas, de habilidad...

El teatro también me sirve como magnifico recurso. Se parece tanto a jugar... Se presta tanto a mostrarse ante los demás como si no fuéramos nosotros mismos, a ensayar nuevos lugares, a pasarlo bien, a perder vergüenzas e inhibiciones, a practicar el hablar ante otros, a elaborar conflictos, a conocer desde cerca las historias, a profundizar en los poemas, o las lecturas sobre los temas que vamos trabajando... En mi clase a toda hora hacemos teatrillos, primero los propongo yo y después ya los niños, como una fuente más de diversión y de conocimiento. Igual dramatizamos un cuento, que algo que nos ha pasado, o que hemos leido...

Un recurso que me sorprende a mi misma por la vida que cobra, por lo útil que es y por los apuros de los que me saca, es un sector del armario, que viene a ser como una despensa, y en el que pongo aquellas cosas más bonitas, raras, llamativas, o brillantes que me dan, que me encuentro, o que 
compro. Algunas veces al guardarlas tengo ya pensado cómo podrían ser utilizadas. Por ejemplo, unos acetatos con rotuladores permanentes, con los que quería que hiciéramos un móvil transparente algún día que "pegara". O unos botes con canela, café en grano, espliego y manzanilla con los que pensé que se podian hacer trabajos "de olor" ... Otras veces las guardo, sencillamente, porque el material me resulta atractivo y pienso que a los niños también les gustará, como fueron unas mazorcas secas de maiz, unas flores de colores y unos corazones de brillo que compré en un viaje a Hungria, unos tules blancos de un taller de trajes de novia, unas fichas desparejadas de juegos diversos, un carrete de cinta roja...

Suelo acumular las que sé que normalmente gustan a los niños: lentejuelas, granos de café, telas "brillosas", peluches pequeños, ganchos del pelo, espejos, cintas, recortes de revistas con fotos sugerentes, bolas de collares rotos, plumas... y diez mil cosas más, con las cuales los trabajos de los niños quedan preciosos y son realizados con mucha alegría. Abrir el armario y echarle un poco de misterio a lo que sale, es remedio infalible para despertar su ansia de novedades, y su inacabable capacidad de asombro.

Me he dado cuenta de que para atraer el interés de los niños utilizo bastante el elemento "novedad" o "sorpresa". Como suelo hacerlo con cosas que me gustan particularmente, me es fácil compartirlas y contagiarlas, $A$ mi además esto me proporciona curiosidad y diversión. Este año ha sido la "Zapatería Pepito" la que les ha movilizado. Traer un par de zapatos de sus casas, ponerles precio, situarlos en la tienda ya montada... Otra cosa que les ha hecho gracia ha sido "La caja de las gafas". Al destaparla hay un espejo y se puede leer: JA, JA, JA. Y el tesoro, los imanes, la linterna, los caleidoscopios... (Diario de clase Jirafas 2005/2006).

También es un buen recurso el recoger cualquier cosa y "hacerla servir", con la sensación medio mágica de que "todo nos vale", porque podemos transformarlo en lo que queramos. A este fin en mi clase hay siempre cestas o cubetas para telas, papeles sobrantes, trozos de juguetes y otras cosas que encontramos los niños, los padres o yo, y a las que damos utilidad.

Recurrir a la naturaleza es otra forma segura de conectar con los niños. A veces salimos a escuchar cantar a los pájaros, a recoger la cosecha de nuestro único almendro, a admirar las jacarandas cuando explotan en sus lilas solemnes, a vernos la cara en los charcos (las pocas veces que llueve), a coger bichos, a acostarnos en la montaña del patio para mirar las formas de las nubes...

Otro recurso muy significativo para mi es volver "ambiente" o tarea los acontecimientos de la cotidianidad, ya sean los "personales" de los niños, los de las familias, los de la escuela... Asi que incluimos en nuestro trabajo y en nuestra conversación los viajes que hacemos, los museos a los que vamos, las fiestas que celebramos, los encuentros, las despedidas, las visitas que aparecen por clase para ilustrarnos sobre algún tema de interés, para enseñarnos un bebé, para tocar el saxofón, o bailarse un buen tango. 


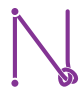

Volumen 6 N. ${ }^{\circ} 48$ enero - junio de 2020 ISSN: 0122-4328 ISSN-E: 2619-6069 pp. $150-172$
Me dicen otras personas que manifiesto entusiasmo en mi quehacer diario, que "saco punta" a las cosas, que puedo observar al grupo y a cada niño, que actúo teniendo en cuenta lo que sé de cada cual... Y probablemente es verdad que estas cosas forman ya parte de mi actuar, pero yo me veo otras cosas más "de dentro", que me han costado y me cuesta de controlar.

Una de ellas es intervenir verbalmente en momentos que mejor sería no hacerlo, ocupando un tiempo que debería ser de los niños. Otra, atreverme a sostener, señalar y valorar las diferencias individuales. Otra, la aceleración entusiástica en la que entro en ocasiones y a la que arrastro a mis alumnos, que llegan a alterarse a veces demasiado. También la dificultad para conectar con algunos de los más callados, más inseguros o más ariscos. Tengo que luchar y mucho contra el empecinamiento que mantengo de querer siempre alcanzar cotas excesivamente "ideales" en las tareas emprendidas. Que la reunión de padres salga muy bien, que el baile quede genial, que todos consigan tener amigos, que yo esté disponible y a la escucha... 0 sea, que todo salga "perfecto". En esto estoy aún... y a lo mejor tengo que trabajar sobre ello siempre, porque es una tendencia muy de mi "piso de abajo" y eso no se quita solo con una declaración de buenos propósitos. Pero al menos está bien saberlo para cazarme los gazapos a mí misma y para intentar no invadir o exigir de más a los niños.

A lo largo de mi vida profesional me he encontrado muchas veces en duda sobre cómo entender e intervenir con algunos de mis alumnos. He ido probando maneras, he ido observando cómo lo hacian otros maestros, he ido equivocándome y he ido aprendiendo. En el recorrido he perdido soledades y miedos, y he ganado seguridad y algunas capacidades para entender cada caso diferenciadamente. En estos momentos hablo desde una posición de acercamiento a los niños y a sus características desde mi intuición, mis sentimientos, mis errores y mi reflexión. Consciente de mis limitaciones y del riesgo de hacer hipótesis en terrenos tan poco "tocables", como son lo afectivo y lo social, pero decidida a no quedarme al margen de sus vidas.

\section{Las palabras que nos hacen}

\author{
El oficio de escribir \\ es pensar en la vida \\ plasmar los sentimientos \\ atrapar la experiencia. \\ El oficio de escribir \\ es derretir angustias \\ explicar desencuentros \\ vestirse de esperanza. \\ El oficio de escribir \\ es crear permanencia
}




\author{
inventar otras vidas \\ retratar nuestros sueños. \\ El oficio de escribir \\ es salvar de lo oscuro \\ mirar desde el adentro \\ caminar sin zapatos. \\ El oficio de escribir \\ es lavar soledades \\ poner huella al recuerdo \\ desearse con otros.
}

Empezaré diciendo que a mi me gusta escribir. Cuando lo hago disfruto de las palabras, del ritmo de la narración, de los sentimientos y reflexiones que convoca en mi la evocación de lo vivido. Me resulta apasionante ponerle nombre a los acontecimientos, afianzar los recuerdos, evitar los olvidos... Y en eso me ocupo cada vez que tengo un rato, y desde que me reconozco. Hago crónica de los acontecimientos de la escuela, escritos pedagógicos que me piden algunas revistas, poesías para niños o mayores, cuentos, columnas...

Para mí escribir es conectarme conmigo misma, escucharme por dentro, sacar a pasear los sentimientos, ordenar mis elucubraciones (en las que siempre se suelen mezclar realidades recuerdos y fantasias). Es escarbar en lo que no entiendo para poder pensarlo, desplegar mis deseos, mis manías y mis emociones. Es hacer saltar mis chispas de imaginación para ver qué fuego encienden, si es que atinan a hacerlo. Para mi escribir es dar forma al pensamiento, y vestirlo, y peinarlo, y darlo a conocer. Es un hecho intimo en el que estoy a solas, pero me siento rodeada de otros, a los que les relato mis cosas. Es buscar compañía, aprobación y aplauso, es regalar palabras a cambio de cariños.

Al principio escribia para tener a mi madre contenta, a ella le encantaban las redacciones y me las hacia hacer y corregir exhaustivamente. Después empecé a escribir para mí misma, sobre todo para quejarme y para divertirme. Mucho tiempo después quise escribir también para otros, por pasar el relevo. Ahora creo que escribo para mi con derecho a compartir con los demás. Escribo por motivos del "piso de arriba": para reflexionar en mi práctica en la escuela, porque hay quienes me dicen que mis escritos les son útiles, porque he comprobado que esta manera de estar en la escuela tiene efectos de salud y placer, y porque tengo la esperanza de que con mis propuestas puede generarse algún cambio. También hay motivos del "piso de abajo", algunos de los cuales ya han sido dichos aquí. Escribo para disfrutar de las palabras, para recordar buenos momentos, para olvidar los problemas, para entender mis pensamientos y afectos, para ser valorada y para hacerme querer.

El proceso de elaboración de mis escritos varía de unas veces a otras. Puedo escribir mientras está ocurriendo algo, aprovechándome de la fuerza y la vitalidad de los acontecimientos, o tomar notas de las ideas principales
Volumen 6 N. ${ }^{\circ} 48$ enero - junio de 2020

ISSN: 0122-4328

ISSN-E: 2619-6069 pp. $150-172$ 
y redactarlo con posterioridad. Puedo escribir movida por una emoción, con el acaloramiento de lo que se siente corriéndome por los brazos, o más tranquilamente, buscando algún rato libre. Otras veces me lleva al papel una palabra, una música, la cara de alguien, un color, una obra de arte, un sueño, un bienestar, una brisa, una pena... En el coche siempre llevo papelitos para las urgencias, que también las hay.

Con cierta frecuencia pienso el título de algo y lo anoto en la agenda, aunque no sepa ni qué va a ser aquello, pero con el tiempo mi memoria lo busca para hacerlo servir, como si estuviera en una despensa, algo así. Mis agendas contienen poemas, frases, nombres, palabras, alguna idea y títulos "vacios". Yo sé que serán algo, les pongo mi esperanza... y con suerte germinan.

Las veces en que no sé cómo empezar a explicar algo, entonces basta con que imagine a unas cuantas personas dispuestas a escucharme... para que ya pueda enhebrar, mejor o peor, el discurso, (asi de habladora soy...) Lo principal es tener algo que transmitir, porque la forma y las palabras seguro que en un momento u otro se encontrarán. Eso sí, se requiere confianza y trabajo. Pero da tanto gusto ver que algo se arma delante de tus ojos, algo que antes no estaba, algo nuevo, y que te pertenece...

Leer lo que escribo me resulta muy curioso. Mientras lo estoy elaborando, lo leo y lo releo, después tengo que dejarlo "posar" un tiempo más o menos largo. Así consigo distanciarme y al volver a leerlo, sé si me gusta o no, si puede servir, o si hay repeticiones, trozos pesados, oscuridad, exageraciones, etc. A veces leo algo que he escrito y descubro cosas de mí que no tenía presentes, que se me escondian. Pondré algunos ejemplos.

Al leer el artículo ya nombrado de "El oficio del maestro es aprender", fui consciente de que yo realmente he aprendido con mi familia, con otros compañeros, y con la experiencia. Al leer "Soñar despierta", descubri mi síntesis personal del oficio de maestra. En mi libro "La oreja verde de la escuela", me di cuenta de que la escucha no es otra cosa que una especie de curiosidad civilizada. En el texto "Un diario no del todo pedagógico", entendi que escribo más de lo que no sé, que de lo que sé. En "Coleccionando momentos", descubrí que no quiero perder los momentos bonitos, los que me ilusionan, porque me generan ganas de seguir en mi profesión. En "El piso de abajo de la escuela" y en "Emociones" supe que, a mi, más que las pedagogías, lo que me interesan son las personas, sus afectos y relaciones.

En "Poesias por alegrías" me di cuenta de que para mí la poesía significa escribir un sentimiento, y que mi deseo era compartir con otros este placer.

Cuando preparo algún libro, el proceso de elaboración suele ser agradable y bonito. Voy recopilando escritos, los ordeno, los corrijo, busco los títulos, organizo la distribución, hago un inicio y un final, pienso quién me gustaría que escribiera el prólogo... Me es sencillo y apasionante imaginarme el libro acabado, y soñarlo, y desearlo. 
Lo que me cuesta es decidirme a incluir en él escritos más sentimentales, o pedazos de poesía. Esa lírica que ya no se lleva, pero que a mí me es cada vez más imprescindible. Por una parte, quiero hacerlo, ya que la poesía es una de mis más caracteristicas formas de expresar lo que siento. Y por otra dudo sobre si encajarán o no estas cosas en textos pedagógicos. Al final gana mi deseo, favorecido por el "espíritu globalizador" que suele inspirarme, y por la opinión cariñosa de los amigos. En esos escritos que añado, muestro mi modo de sentir, recojo y plasmo instantes, compongo collages con pedacitos de la realidad y de mí. Estas escrituras me entretienen mucho, y me dan un cierto descanso para el alma, porque una vez escrita una emoción, ya no tengo que sostenerla adentro, asi que se me descansa la memoria, haciendo hueco para más poemas, para poder seguir diciéndome...

En el libro Mi escuela sabe a naranja, tuve que elegir qué poemas servirían de colofón a cada uno de los artículos. Este es el que sigue a un artículo que habla del juego:

Yo jugaba a lavar, a barrer y a fregar los platos.

Jugaba a ser cantante, a vender "collaritos", a coleccionar botones y a inventar.

Jugaba a hacer de maestra, a probarme tacones y a escuchar lo que hablaba todo el mundo, a mirar las hormigas de mi patio y a soñar.

Y dibujaba en la arena, y escribia en las hojas y machacaba ladrillos con un poco de vinagre, de bicarbonato del abuelo, saliva, agua y sal.

También hacia hoyos en la playa, bolas, puentes o castillos con arena morena, la húmeda, con arena chorreando, la empapada, y con arena seca, que era la que hacía de "azúcar." Y primero me saltaba los pilones de la calle, las rocas, las vallas o las piedras viejas. Y después salté a la comba como los propios ángeles.

En mis libros también me es difícil ajustarme al número de páginas y de fotografias que se me requieren. No veo el modo de cortar nada, todo me parece sumamente necesario... Suelo ir escribiendo en el Diario de clase lo que me llama la atención, lo que percibo digno de ser recordado, lo que me puede servir para entender algo, para explicárselo a otros, lo que tiene fuerza y belleza. También escribo sobre lo que no entiendo, lo que me sienta mal, lo que admiro o los datos que seguramente necesitaré para relatar una experiencia, un proceso, un proyecto de trabajo o una discusión en varias fases. En fin, que apunto lo que me gusta y me parece bueno conservar, y con ese material elaboro mis artículos. En algunas ocasiones, escribo al mismo tiempo que están ocurriendo las cosas, como si temiera perder el aroma y la energía de las vivencias.

En los textos voy y vengo de los pilares teóricos en los que he aprendido a la cotidianidad y a las teorías que voy construyendo y elaborando a partir 
de los niños, de mí y de lo que va pasando. Quisiera pensar que se puedan reconocer sin demasiado esfuerzo mis deseos de acompañar a los niños en su crecer escuchándolos con aquella oreja verde que inventó Rodari. En su aprender a partir de la significación y construcción de los conocimientos, como nombraba Piaget. En su investigar en grupo cuando hacen proyectos de trabajo "con intencionalidad y de todo corazón", como definía Kilpatrick. En sus tanteos a través del pensamiento y las emociones, como sugería Dewey. En el percibir global de Decroly. En el respeto a sus ritmos, a su cuerpo y a sus momentos sensibles, como nombraba María Montessori. En su magnífica relación con la naturaleza (Froebel). En su creativo acercamiento a la estética, como señalaba Malaguzzi. En su despegar hacia los otros a partir de la calma y la seguridad emocional, como dice Vicenç Arnaiz. Espero que se vean también mis intentos de recopilar afectos y recursos aprovechando las visitas de los padres de los niños y otras personas que se acercan a la escuela. Algo parecido a lo que hacía don Lorenzo Milani en Barbiana. Son tantas las fuentes en las que he bebido... También se ve en ellos mi afición a coleccionar las palabras de los niños, sus dibujos y demás producciones, y el acontecer de los procesos afectivos que llenan de vida la compleja y hermosa cotidianidad de la escuela.

En el último texto aparece lo que pienso, lo que siento, lo que dudo, lo que ignoro y lo que deseo en el día a día en mi escuela.

Desde hace un tiempo estoy intentando hacer conscientes los movimientos que hago, o las vías que utilizo para hablar con los niños de los sentimientos, de los asuntos de relación, y de todas esas cosas del piso de abajo emocional que tanto nos implican.

Una de las principales estrategias que utilizo es el ir hablando de los acontecimientos cotidianos, poniendo en común lo que sabe y siente cada cual sobre el asunto de que se trate, o sobre los afectos movilizados en las relaciones entre ellos.

Otro camino es incluir el cuerpo: mirarlo, cuidarlo, moverlo, compartirlo, estar contentos con él, usarlo para acariciar, pintar, trabajar, dramatizar, bailar...

También dar amplia y preferencial cabida al juego libre, a la experimentación, a la libre elección de amigos, actividades, materiales, talleres...

Y por supuesto, tener en cuenta significativamente a las familias, punto referencial importantísimo en estas cuestiones de adentro. Permitir y potenciar que vengan, que aporten, que miren, que cuenten, que estén.

Para mi es un descanso hojear mis escritos y notar que en ellos se translucen varios de mis intereses más genuinos: mi pasión por las palabras, mi alegría al estar haciendo un trabajo que me agrada, y el placer de haber podido reunir una cosa y la otra en esta síntesis que vivo de acompañar a los niños rodeando de palabras los vínculos y los encuentros. En mi narrativa se 
refleja, pues, mi valoración ferviente de la consideración del mundo afectivo de todos los implicados en la escuela, a lo que suelo llamar "el piso de abajo". Así como el universo relacional que se abre y se estrena como puede en los trabajosos y bonitos inicios de la socialización.

escribo esta pequeña historia de la presencia del perro mongol en mi clase, porque tengo la necesidad de explicar que el hecho de contarles a los niños algo que me suponía un placer, como esta película, no es algo casual, sino algo buscado conscientemente, porque con el tiempo me he dado cuenta de que no tengo que desperdiciar las ocasiones de contagiar lo que siento, de dejarme ver, de implicarme y caminar al lado de los niños. Pero no solo en los aprendizajes, sino también en los sentimientos. Compartir una emoción estética y vital con mis alumnos me hace situarme en una profunda sintonía con ellos, a los que intuyo sensitivos, atentos y recopiladores de nuevos datos sobre el género humano. Datos que les van a servir, espero, para comprenderse mejor a si mismos y para comprender a las demás personas. Sentimientos parecidos tuve cuando me adentré con los niños a conocer el cuadro de Las Meninas, o cuando leimos juntos Alfanhui, Platero y yo, La luna nueva, Asi es la vida, El coleccionista de momentos... Y es que compartir la belleza con los niños, curiosear la realidad con ellos, transmitirles nuestras pasiones favoritas, a lo mejor son cosas que deberiamos incluir en el curriculum, en lugar de rehuirlas, o tratarlas como excentricidades.

Y es que para mi esta película no ha sido algo banal, sino que me ha hecho pensar y mucho en esta extraña vida que vivimos ahora. Tan alejados de la naturaleza, de las realidades corrientes, de la pura lógica... Tan inmersos en un mundo individualista, sofisticado, consumista, competitivo, fiero... Un mundo en el que se nos han olvidado el pan, la leche, el queso, el frío. En el que cerramos los ojos al lobo, al buitre y demás peligros verdaderos. En el que hemos dejado a un lado valores como mirarnos a la cara, cuidarnos, escucharnos, protegernos. Y hemos puesto "en ignorancia" la seguridad que dan las palabras de los padres, sus manos, su ley, su acompañamiento y su cariño. Metidos en las orejeras de nuestro pequeño "alrededor", hemos criado callos en el sentido común y ahora apenas si nos da tiempo a ver la forma de las nubes, a criar un perrillo, o a agradecer la vida. Desde aqui una llamada de alerta para "volver a madre" y recuperar los recursos naturales que se nos ofrecen a poco que miremos adentro y alrededor. Yotra llamada a compartir los sentimientos que nos conmueven con los niños. No hay mejor regalo.

En mis libros leo risas, curiosidades, juego, sorpresas y aprendizajes. Leo que el ambiente en la escuela es un valor a cultivar y enriquecer. Leo que las cosas de cada día son una fuente de salud, de saber y de placer.

Entre líneas también leo que he sentido profundamente las experiencias que cuento. Y que he pensado en ellas mientras las vivia, mientras las compartía con otros y mientras las escribía. Entre líneas veo las caras de los niños de los que hablo, oigo sus voces, recuerdo los tantos momentos que han tejido esta maraña de afectos que me mantiene llena y abrigada. Atrapada y libre. Por suerte y por deseo. 


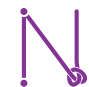

Volumen 6 N.o 48 enero - junio de 2020 ISSN: 0122-4328 ISSN-E: 2619-6069 pp. $150-172$

\section{Referencias}

Arnáiz, V. (2002). Prólogo. En C. Díez Navarro, El piso de debajo de la escuela. Editorial Gráo.

Camus, A. (1994). El primer hombre. Tusquets.

Díez Navarro, C. (2007). Las leyes de las ropas. En C. Diez Navarro, Mi escuela sabe a naranja. Editorial Gráo.

Sampedro, J. L. (1992, 12 y 13 de marzo). El educador y sus fronteras. Enseñar y aprender en ellas [Conferencia]. Iv Jornadas de Investigación educativa en el ICE, Universidad de Lleida.

Tagore, R. (1966). Obra escogida. Editorial Aguilar. 


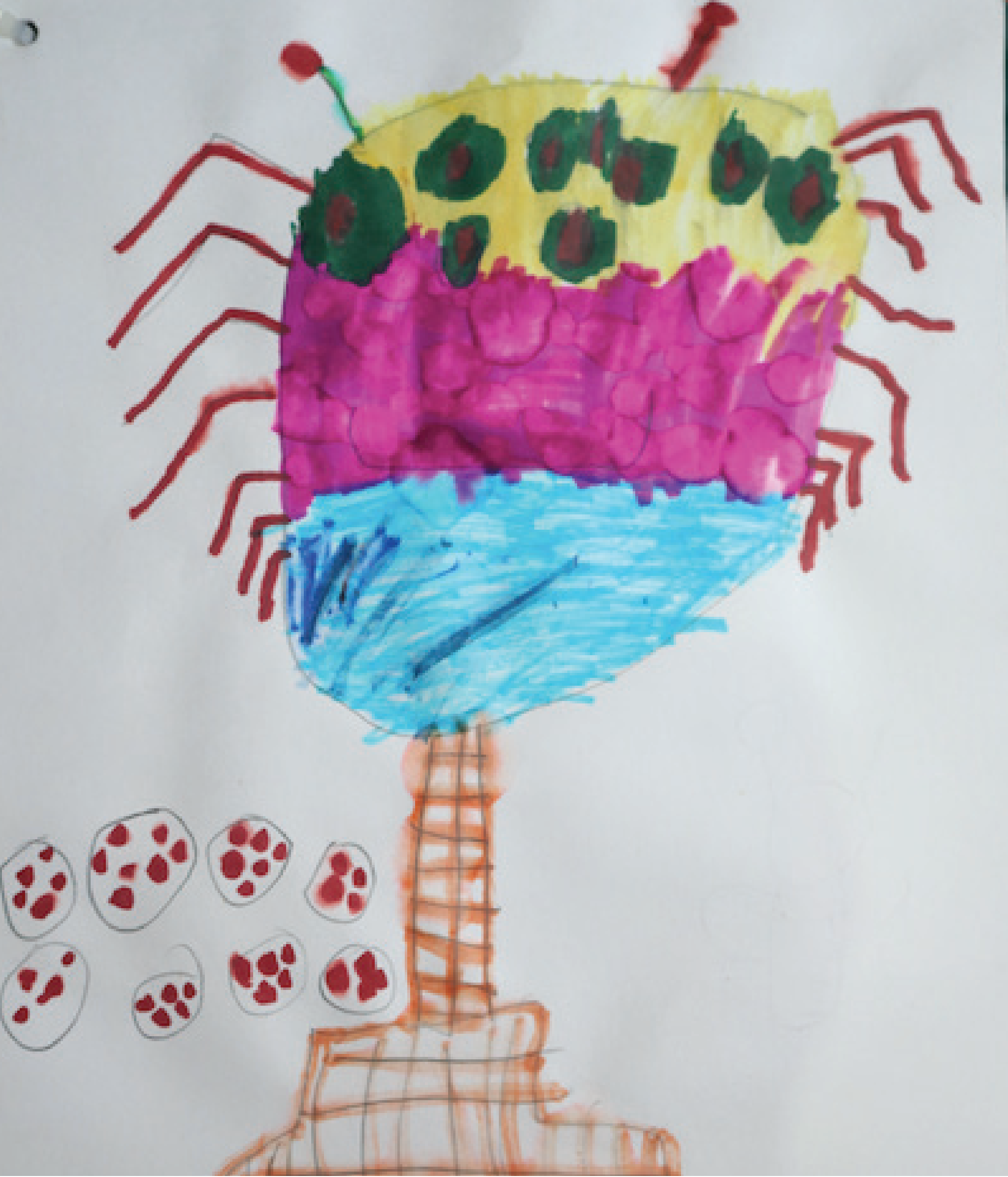

autor: Andrés Julián Castañeda González título : Insecto-araña

año : 2014 